\title{
Corrigendum: The Forensic Restrictiveness Questionnaire: Development, Validation, and Revision
}

\author{
Jack Tomlin ${ }^{1 \star}$, Birgit Völlm ${ }^{1}$, Vivek Furtado ${ }^{2}$, Vincent Egan ${ }^{3}$ and Peter Bartlett ${ }^{4}$ \\ ${ }^{1}$ Department of Forensic Psychiatry, University of Rostock, Rostock, Germany, ${ }^{2}$ Mental Health and Wellbeing, Warwick \\ Medical School, University of Warwick, Coventry, United Kingdom, ${ }^{3}$ Centre for Family and Forensic Psychology, University of \\ Nottingham, Nottingham, United Kingdom, ${ }^{4}$ School of Law and Institute of Mental Health, University of Nottingham, \\ Nottingham, United Kingdom
}

Keywords: forensic, mental health, restrictive, autonomy, FRQ, forensic restrictiveness questionnaire, psychometric

\section{OPEN ACCESS}

Edited and reviewed by: Alexander lan Frederic Simpson, Centre for Addiction and Mental Health (CAMH), Canada

*Correspondence: Jack Tomlin jack.tomlin@med.uni-rostock.de

Specialty section This article was submitted to Forensic Psychiatry, a section of the journal

Frontiers in Psychiatry

Received: 06 January 2020 Accepted: 13 February 2020 Published: 25 February 2020

Citation:

Tomlin J, Völlm B, Furtado V, Egan V and Bartlett $P$ (2020) Corrigendum:

The Forensic Restrictiveness

Questionnaire: Development, Validation, and Revision

Front. Psychiatry 11:128

doi: 10.3389/fpsyt.2020.00128

\section{A Corrigendum on}

The Forensic Restrictiveness Questionnaire: Development, Validation, and Revision by Tomlin, J., Völlm, B., Furtado, V., Egan, V., and Bartlett, P. (2019). Front. Psychiatry 10:805. doi: $10.3389 /$ fpsyt.2019.00805

In the original article, there was an error. The Forensic Inpatient Quality of Life Questionnaire Short Version (FQL-SV) was incorrectly called the Forensic Quality of Life Profile - Short Version (FQL-SV).

A correction has been made to the Instruments section, subsection Forensic Quality of Life Profile-Short Version (FQL-SV), Paragraph 1:

"Forensic Inpatient Quality of Life Questionnaire - Short Version (FQL-SV)

Patient quality of life was measured with the short version of the Forensic Inpatient Quality of Life Questionnaire - Short Version (FQL-SV; 45, 46). This scale was developed in The Netherlands and translated into English by its authors. The FQL-SV is comprised of 20 items. It asks patients about a range of topics including leave, safety, food, personal hygiene, sexuality, and relationships with other residents."

The authors apologize for this error and state that this does not change the scientific conclusions of the article in any way. The original article has been updated.

Copyright () 2020 Tomlin, Völlm, Furtado, Egan and Bartlett. This is an open-access article distributed under the terms of the Creative Commons Attribution License (CC BY). The use, distribution or reproduction in other forums is permitted, provided the original author(s) and the copyright owner(s) are credited and that the original publication in this journal is cited, in accordance with accepted academic practice. No use, distribution or reproduction is permitted which does not comply with these terms. 